\title{
Outpatient percutaneous nephrolithotomy in a renal transplant patient: World's first case
}

\author{
Kristen McAlpine; Michael J. Leveridge, MD, FRCSC; Darren Beiko, MD, MBA, FRCSC
}

Department of Urology, Queen's University, Kingston General Hospital, Kingston, ON

Cite as: Can Urol Assoc J 2015;9(5-6):E324-8. http://dx.doi.org/10.5489/cuaj.2414 Published online May 13, 2015.

\section{Abstract}

Percutaneous nephrolithotomy (PCNL) is an established safe and effective surgical treatment option for renal calculi in renal allografts. The advent of tubeless PCNL has led to reports of ambulatory or outpatient PCNL. This case report describes the successful outpatient management of a 49-year-old female with a symptomatic renal pelvic calculus in her transplanted kidney. Tubeless PCNL successfully removed the stone, free of complication, and the patient was discharged 2 hours and 17 minutes after the procedure in stable condition with minimal pain. This is, to the best of our knowledge, the first successful case of outpatient tubeless PCNL in a transplanted kidney.

\section{Introduction}

Percutaneous nephrolithotomy (PCNL) is an accepted and widely used approach to extract large renal calculi. Since its description in the 1970s, ${ }^{1}$ surgical and technological advances have obviated the need for routine nephrostomy tube placement. ${ }^{2-8}$ Tubeless PCNL, with ureteral stenting, has been shown to decrease patients' analgesic requirements and hospital length of stay.9,10 Although hospitalization is standard practice after PCNL, reports have described success with outpatient management. ${ }^{11,12}$ This case report is the first to describe successful outpatient PCNL in a renal transplant patient.

\section{Case report}

A 49-year-old female presented to her community hospital with hematuria and lower abdominal pain over the preceding 48 hours. She had received her second cadaveric kidney transplant 6 years previously for end-stage renal disease of unknown etiology. On presentation she was afebrile and hemodynamically stable. Urine was positive for blood, but negative for nitrites or pyuria. Creatinine was $164 \mu \mathrm{mol} / \mathrm{L}$ (estimated glomular filtration rate $29 \mathrm{~mL} / \mathrm{min} / 1.73 \mathrm{~m}^{2}$ ), slightly elevated from her baseline of $150 \mu \mathrm{mol} / \mathrm{L}$. An ultrasound scan showed a large renal stone in the lower pole of the allograft kidney. Intravenous antibiotics were initiated and the patient was transferred to our tertiary care centre.

At our institution, a computed tomography scan revealed a $14 \times 12 \times 11-\mathrm{mm}$ stone located in the renal pelvis (Fig. 1a, Fig. 1b). There was mild hydronephrosis, yet the parenchyma of the graft was preserved. There was no evidence of a urinary tract infection $(\mathrm{UTI}) /$ sepsis and the patient's pain responded to oral analgesia. The surgical options were discussed and a decision was made to proceed with the PCNL. Informed consent was obtained and a 1-week course of levofloxacin was prescribed for UTI prophylaxis.

On the morning of the procedure, a stress dose of $100 \mathrm{mg}$ intravenous (IV) hydrocortisone was administered. Cefazolin $1 \mathrm{~g}$ IV was given prior to induction of general anesthesia. Flexible cystourethroscopy was performed and a 5Fr openended ureteral catheter was passed up the left transplanted ureteral orifice over a 0.035" guidewire. A Foley catheter was placed to straight drainage and the patient was repositioned supine for percutaneous access. Retrograde ureteropyelography outlined the allograft kidney's collecting system, demonstrating renal transplant inversion and a slight filling defect in the renal pelvis corresponding to the solitary stone (Fig. 2). A lower pole puncture was performed on the first pass into an anterior calyx using the 'eye of the needle' technique (Fig. 3). A stiff 0.038" guidewire was advanced into the bladder and secured as the safety wire (Fig. 4). Tract dilation was performed and the percutaneous sheath was advanced into the renal pelvis (Fig. 5). The calculus was immediately evident on rigid nephroscopy and removed with duckbill graspers. Final nephroscopic and fluoroscopic examination confirmed a stone-free state. Bleeding was negligible throughout. A $22-\mathrm{cm} \times 6 \mathrm{Fr}$ double J stent was placed with the proximal coil in the renal pelvis and the redundant distal coil in the bladder (Fig. 6). The 


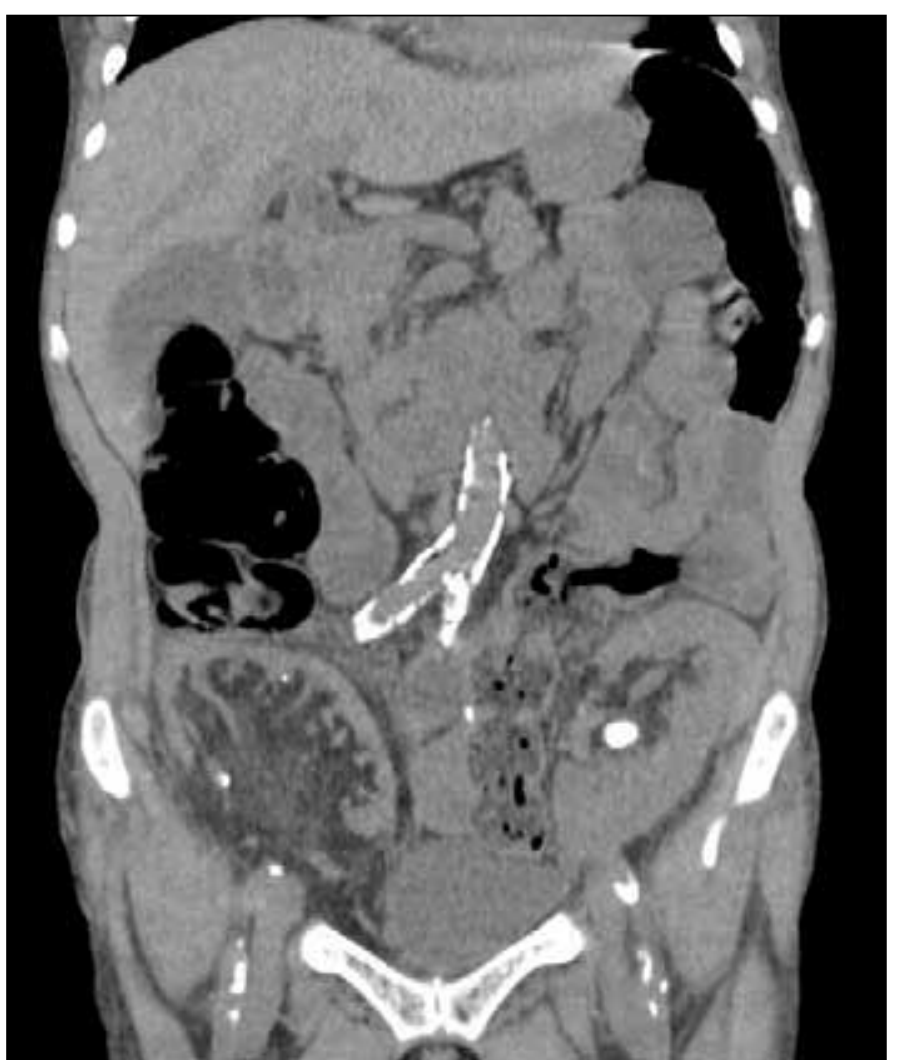

Fig. 1a. Coronal computed tomography image showing stone in the left iliac fossa renal allograft.

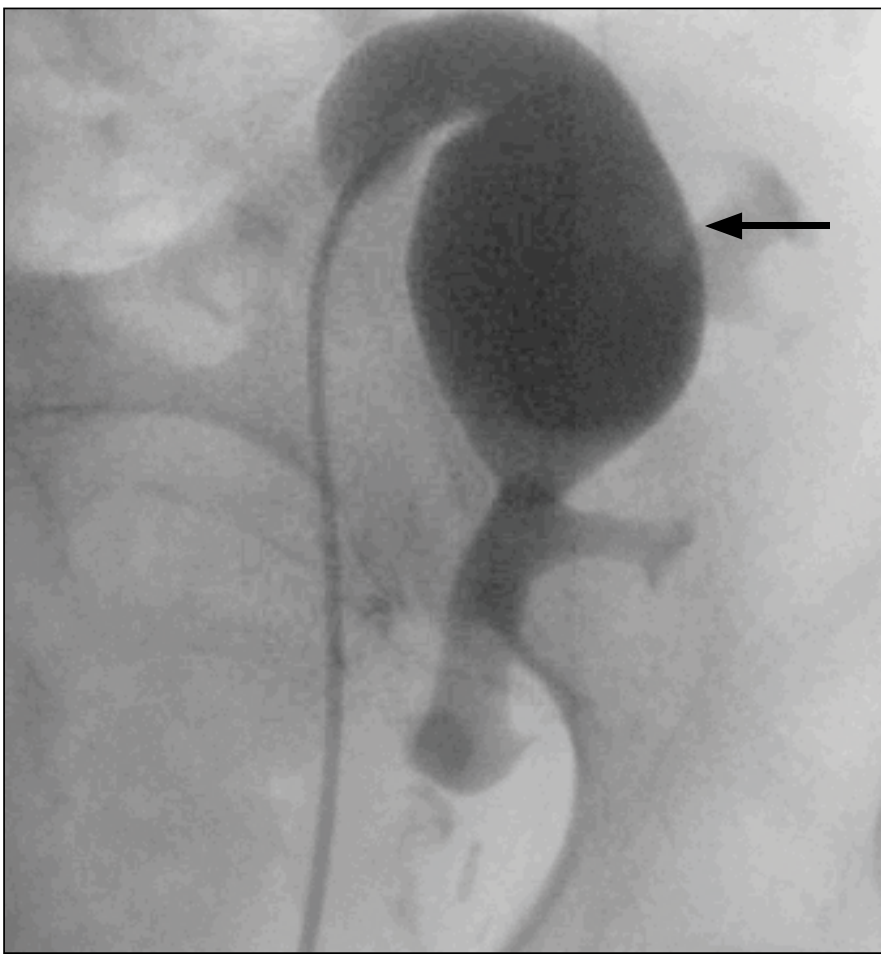

Fig. 2. Retrograde pyelography showing slight filling (stone) in the renal pelvis of the allograft.

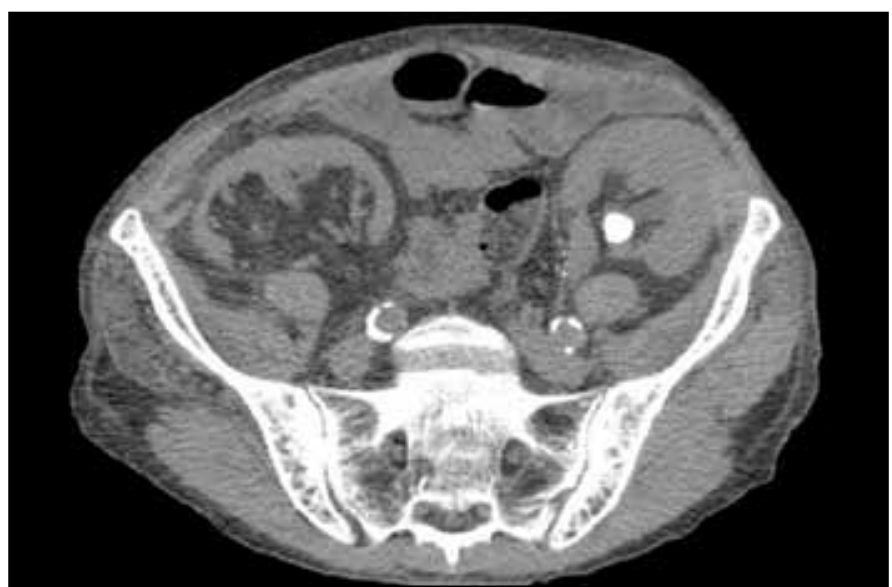

Fig. 1b. Axial (transverse) computed tomography image showing stone in the left iliac fossa renal allograft.

sheath was removed, leaving a temporary safety $5 \mathrm{Fr}$ openended ureteral catheter in the renal pelvis. Inspection of percutaneous incision revealed no bleeding and the ureteral catheter was removed, terminating the procedure. The total operative time was 81 minutes.

In the recovery room, the patient experienced minimal pain. She met all of our previously published intra-operative and postoperative criteria for consideration of outpatient

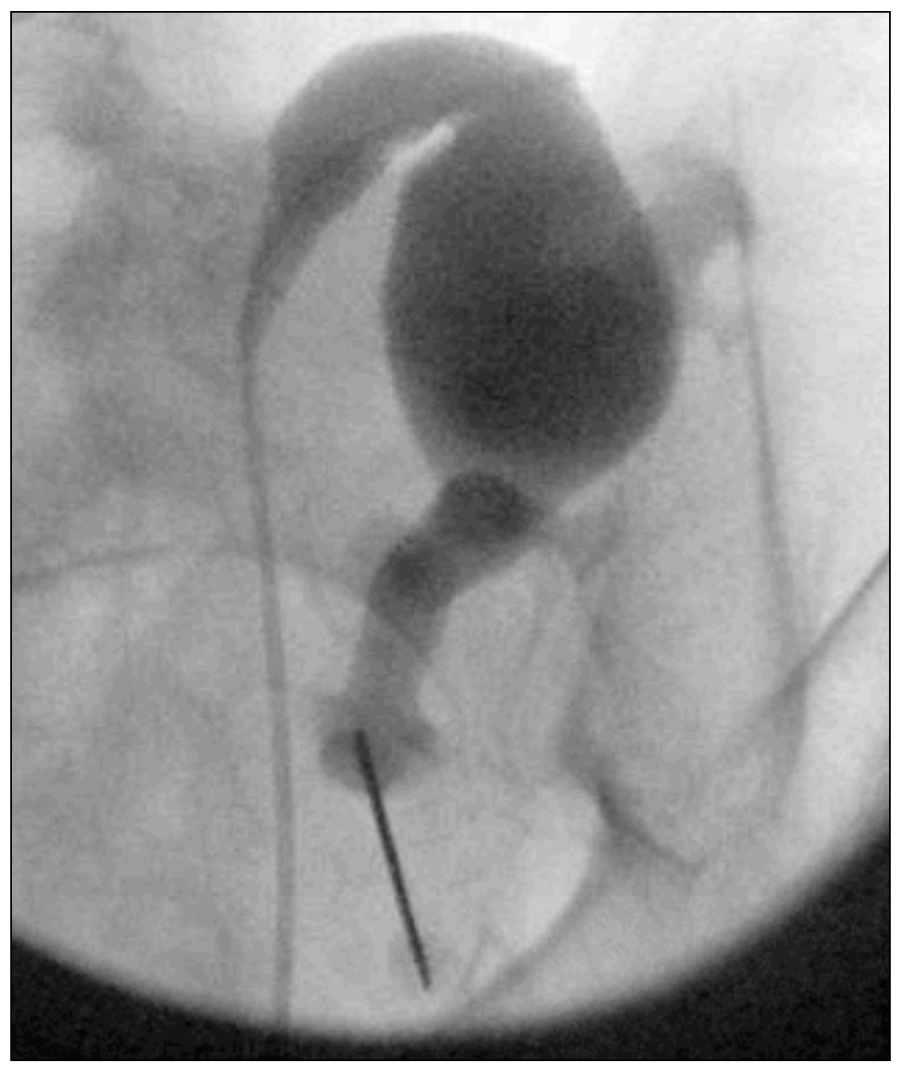

Fig. 3a. Percutaneous puncture of the lower pole calyx. 


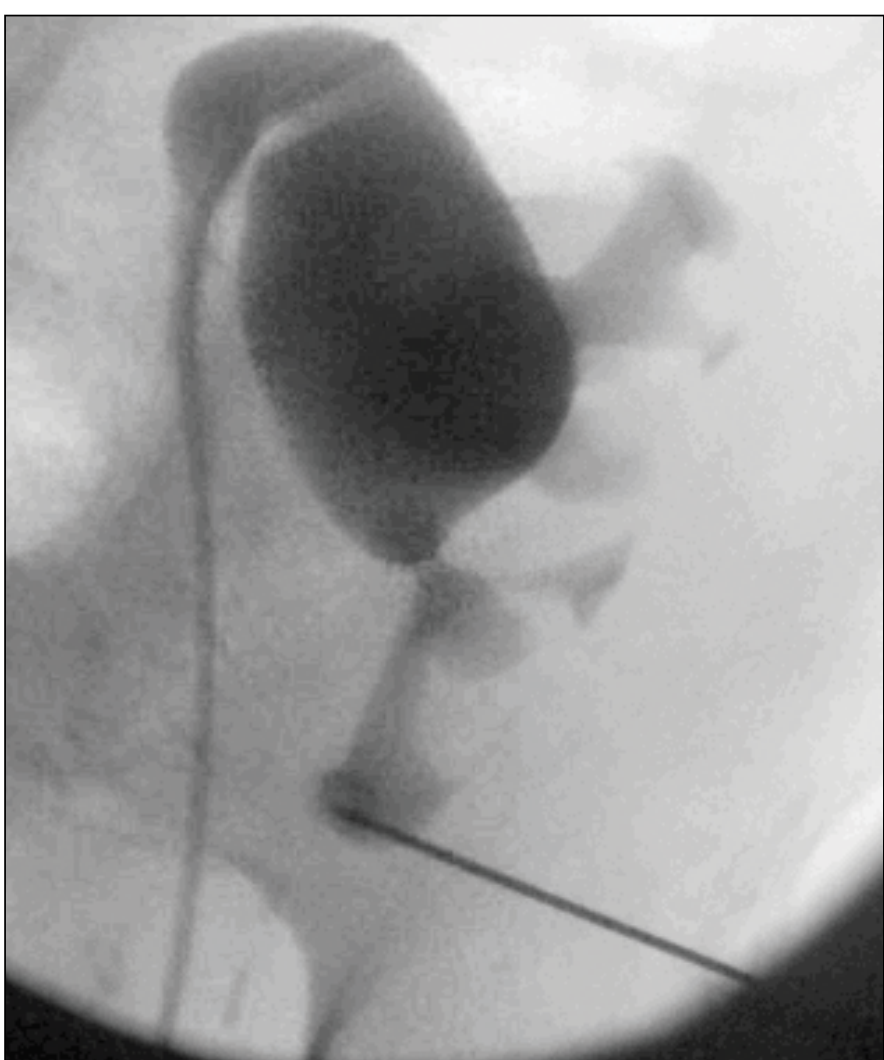

Fig. 3b. Bi-planar fluoroscopy to confirm the depth of the percutaneous puncture.

management. ${ }^{11}$ After 2 hours and 17 minutes in the postanesthetic care unit, she was discharged in stable condition.

The patient was seen for follow-up on postoperative days 10 and 25. Other than mild stent colic and mild hematuria, she was stable and well. KUB (kidney, ureter, bladder) X-ray and ultrasound showed no evidence of residual fragments. The stent was removed cystoscopically. Stone analysis revealed a mixed stone containing calcium oxalate (major) and calcium carbonate/phosphate with magnesium ammonium phosphate (minor).

\section{Discussion}

Urolithiasis is an uncommon, but potentially catastrophic complication of renal transplantation. The risk of ureteral obstruction and subsequent graft compromise contribute to the urgent manner in which management is required. Additionally, patients are chronically immunosuppressed following transplantation predisposing them to sepsis should infection complicate the stone.

The extra-anatomical location of a renal allograft becomes an important consideration when planning stone extraction. ${ }^{13}$ Extracorporeal shock wave lithotripsy can be used; however, targeting the shock wave directly onto the stone can be difficult due to the proximity of the bony pelvis. ${ }^{14}$

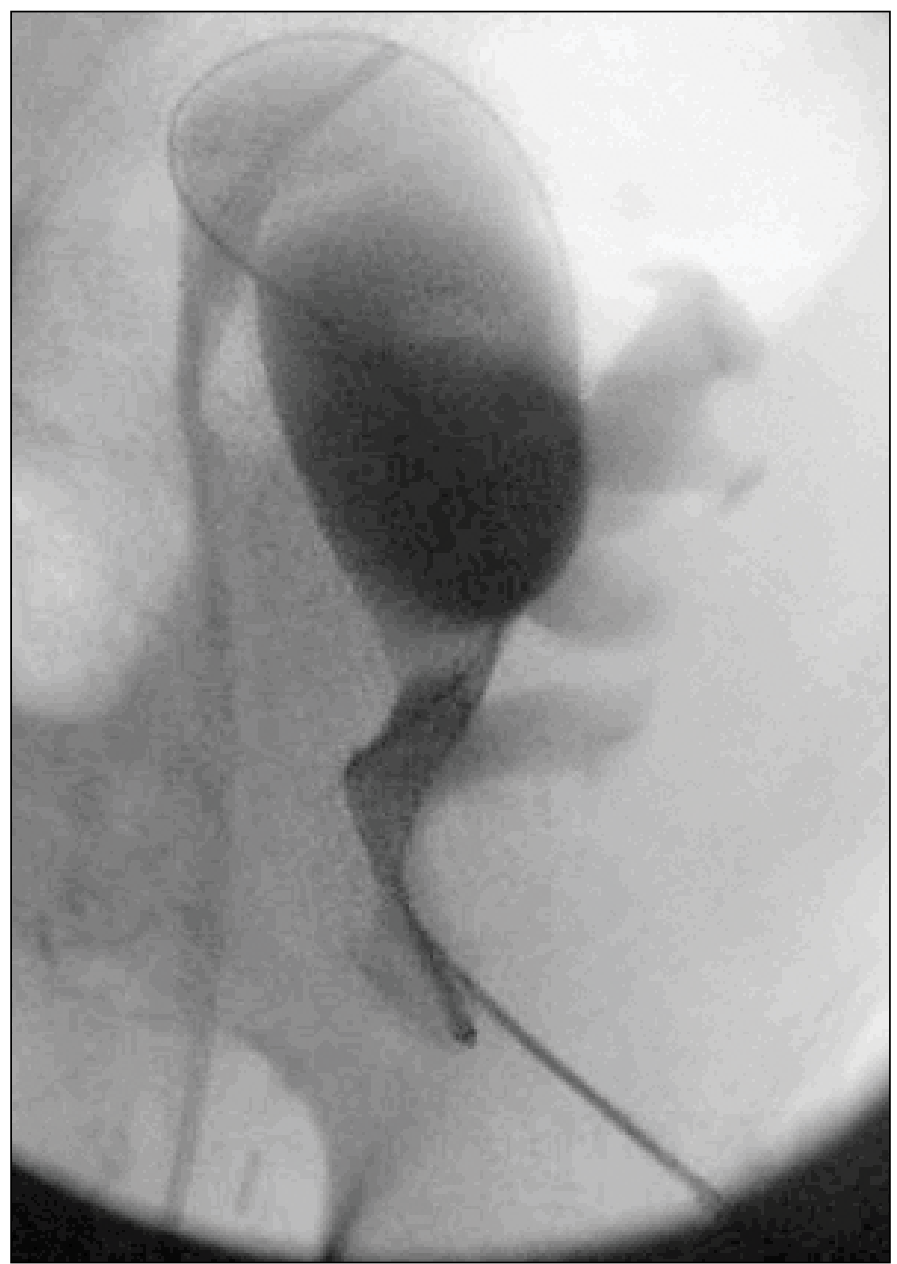

Fig. 4. Coiling of the percutaneous guidewire in the intrarenal collecting system.

Ureteroscopic approaches are also possible, but can be challenging as the neo-ureteric orifice is often superior in the bladder and difficult to access. ${ }^{13}$ Additionally, the absence of native connective tissue may increase the risk of ureteral injury during instrumentation. ${ }^{14}$

Traditional and tubeless PCNL are safe and effective in transplanted kidneys, but there are unique considerations. ${ }^{8,15}$ With the graft located in the iliac fossa, access is typically by way of an anterior calyx with the patient in a supine position. ${ }^{15}$ The proximity of bowel loops and iliac blood vessels introduce the possibility of injury to these structures. ${ }^{16}$ Intra-operative ultrasound can be used to assess anatomy before access is attempted. ${ }^{16}$ Additionally, immunosuppressants may prolong postoperative recovery due to delayed wound healing, and increased risk of infection. ${ }^{15}$

There have been significant advances in the percutaneous extraction of renal calculi. ${ }^{2-10}$ Review articles have highlighted the need for minimal intra-operative bleeding, negligible residual stone burden, and one to two attempts at renal access when considering tubeless approaches. ${ }^{6,17}$ 


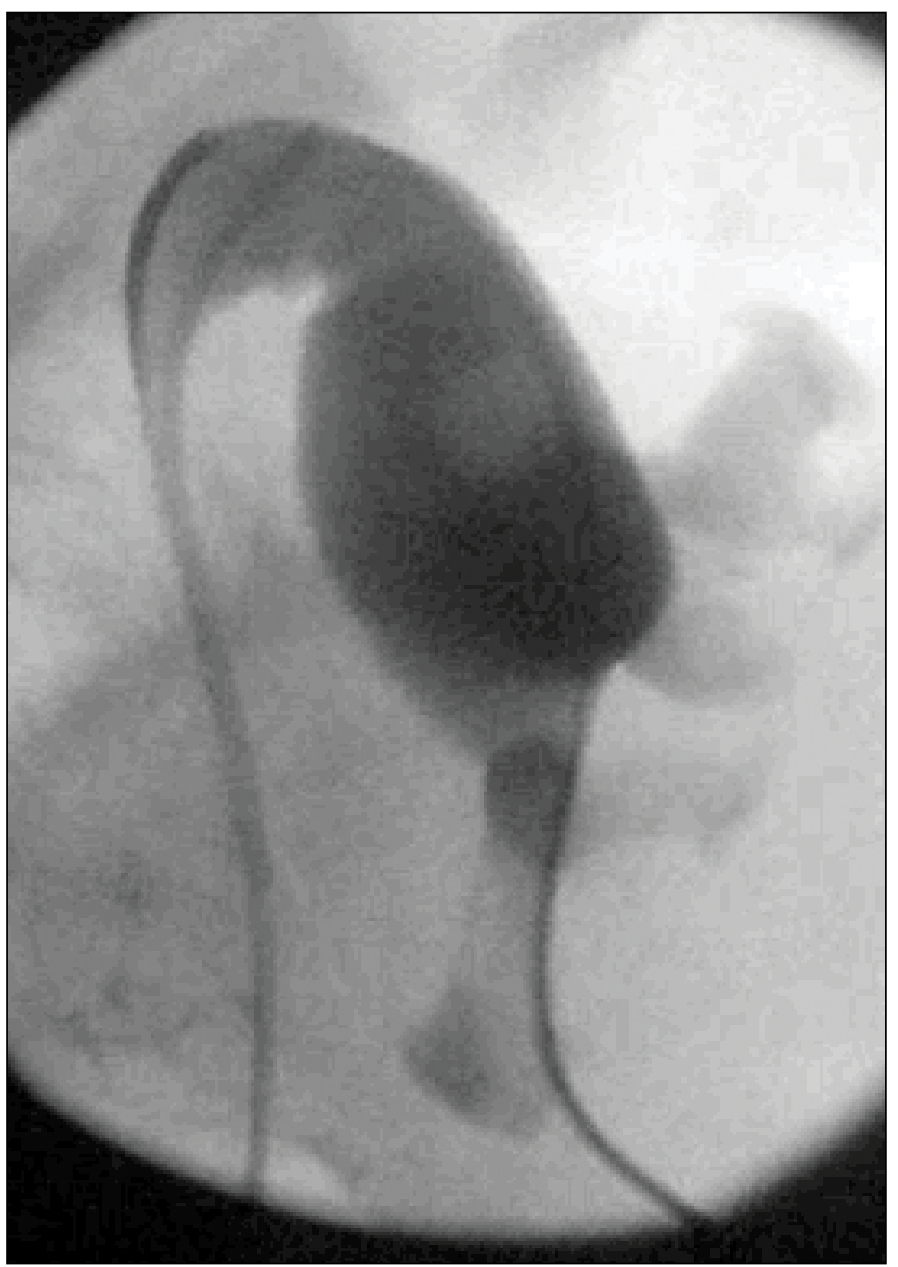

Fig. 5. Advancing the Kumpe catheter down the ureter.

Recently, the ability to perform tubeless PCNL as an outpatient procedure has been reported. ${ }^{11,12}$ The capacity to routinely complete PCNL as day surgery is highly attractive due to the anticipated healthcare cost savings and the potential reduction in nosocomial infections. Two case series published in 2010, described good outcomes with ambulatory PCNL in carefully selected patients. ${ }^{11,12}$ Since then, outpatient management has been performed in more complex patients, including a case report on tubeless PCNL for bilateral staghorn stones. ${ }^{18}$ As we continue to shift toward ambulatory surgery in urology, performing outpatient PCNL in a transplanted kidney is an extension of application of the ambulatory approach to increasingly complicated cases. We do not advocate routine ambulatory PCNL in transplant kidneys in all centres. In fact, this approach is inappropriate in most institutions. At our institution, we have developed a fairly robust clinical care pathway for outpatient PCNL and we have slowly expanded our inclusion criteria to increasingly complex patients and stones. Our experience over the past 7 years, combined with the small stone size and uncomplicated operation,

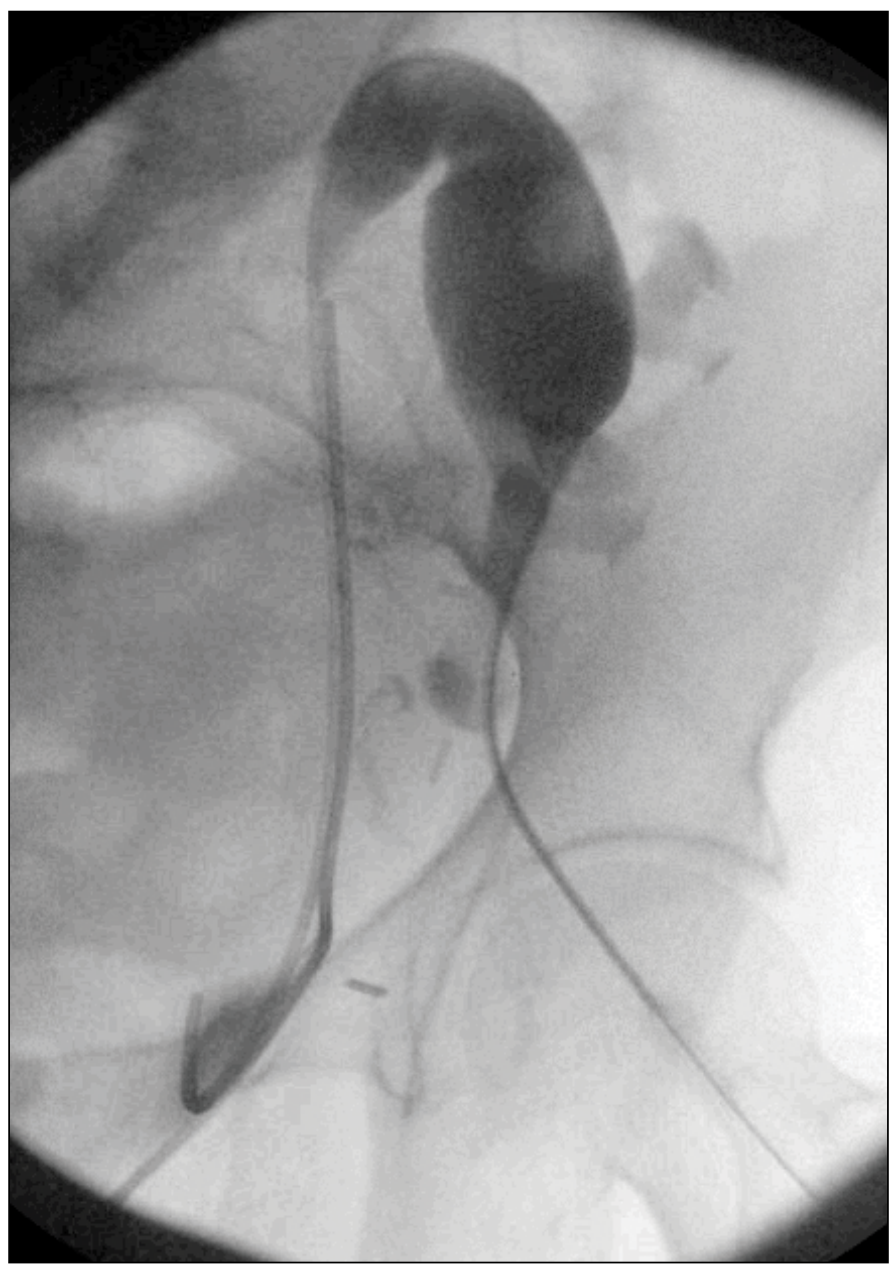

Fig. 6. The Kumpe catheter traversing the ureter into the bladder (note: the filling defect more obvious).

permitted us to utilize our ambulatory approach in this particularly complex transplant case.

In this particular case, the retrograde ureteropyelogram demonstrated the kidney was transplanted upside down in the iliac fossa. In the literature, renal transplant inversion is often intentional but can also be unintentional, ${ }^{19-20}$ and in this case it was most likely unintentional. It is unknown if renal transplant inversion causes urinary stasis and kidney stones.

\section{Conclusion}

To the best of our knowledge, this was the world's first case of ambulatory PCNL in a renal allograft. Although there are unique challenges in accessing urolithiasis in graft kidneys, intra-operative parameters are still critical to plan postoperative care. With negligible bleeding, lack of residual stone burden, and stable parameters in the recovery room, ambulatory care was appropriate and successful in this renal transplant patient. 


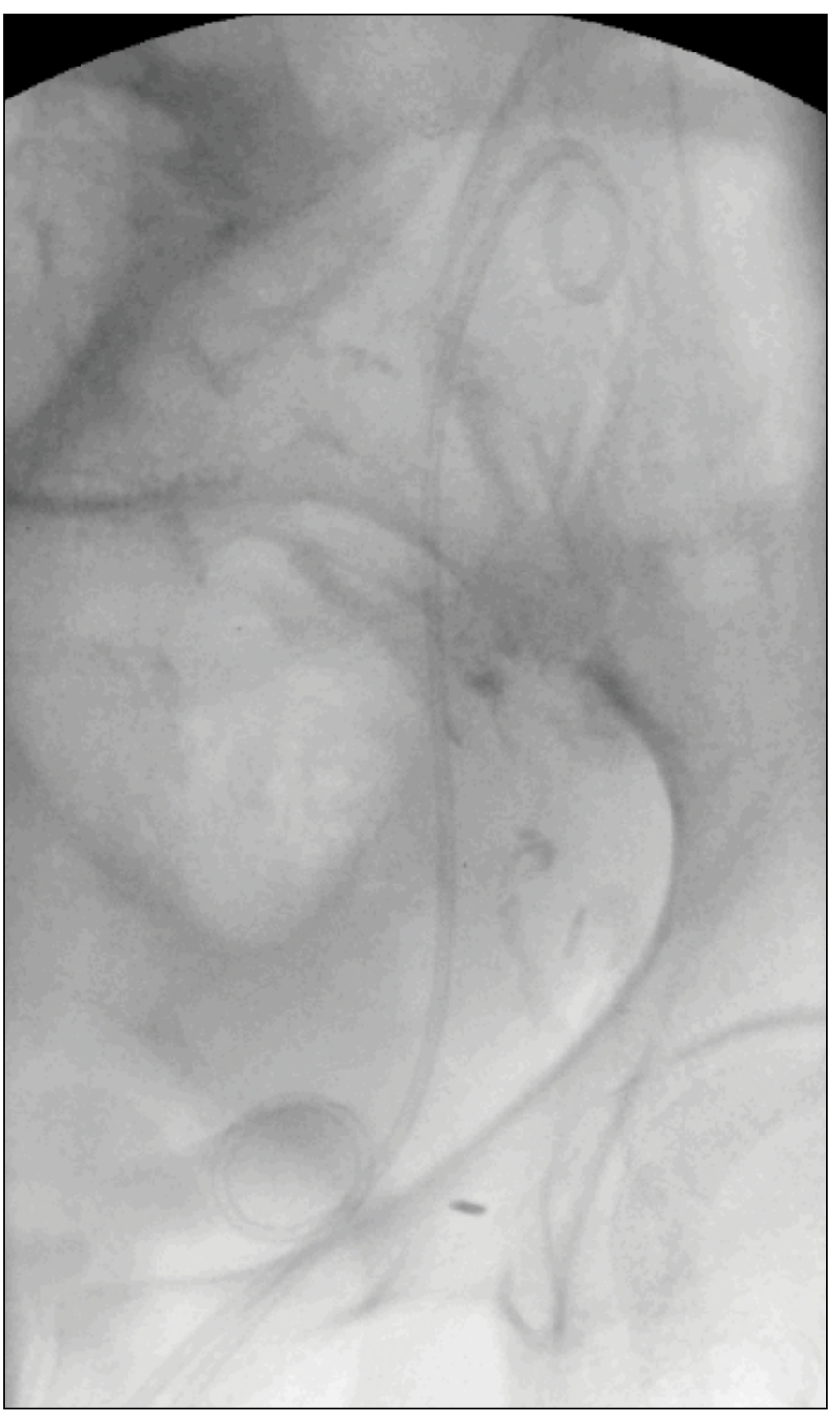

Fig. 7. Postoperative fluoroscopic image showing the stent in the proper position.

Competing interests: The authors declare no competing financial or personal interests.

\section{References}

1. Fernstrom I, Johansson B. Percutaneous pyelolithotomy. A new extraction technique. Scand I Urol Nephrol 1976:10:257-9.

2. Bellman GC, Davidoff R, Candela J, et al. Tubeless percutaneous renal surgery. J Urol 1997;157:1578-82. http://dx.doi.org/10.1016/S0022-5347(01)64799-2

3. Shah HN, Kausik VB, Hegde SS, et al. Tubeless percutaneous nephrolithotomy: A prospective feasibility study and review of previous reports. BJU Int 2005;96:879-83. http://dx.doi.org/10.1111/i.1464410X.2005.05730.x

4. Gupta V, Sadasukhi T, Sharma K, et al. Tubeless and stentless percutaneous nephrolithotomy. BJU Int 2005;95:905-6. http://dx.doi.org/10.1111/i.1464-410X.2005.05432.x

5. Crook TJ, Lockyer CR, Keoghane SR, et al. Totally tubeless percutaneous nephrolithotomy. J Endouro 2008;22:267-71. http://dx.doi.org/10.1089/end.2006.0034

6. Wang J, Zhao C, Zhang $C$, et al. Tubeless vs standard percutaneous nephrolithotomy: A meta-analysis. BJU Int 2011;109:918-24. http://dx.doi.org/10.1111/i.1464-410X.2011.10463.x

7. Amer T, Ahmed K, Bultitude M, et al. Standard versus tubeless percutaneous nephrolithotomy: A systematic review. Urol Int 2012;88:373-82. http://dx.doi.org/10.1159/000336145

8. Istanbulluoglu MO, Cicek T, Ozturk B. Percutaneous nephrolithotomy: Nephrostomy or tubeless or totally tubeless? Urology 2010;75:1043-6. http://dx.doi.org/10.1016/i.urology.2009.06.104

9. Garofalo M, Pultrone CV, Schiavine R, et al. Tubeless procedure reduces hospitalization and pain after percutaneous nephrolithotomy: Results of a multivariate analysis. Urolithiasis 2013;41:347-53. http:// dx.doi.org/10.1007/s00240-013-0565-8

10. Crook TJ, Lockyer CR, Keoghane SR, et al. A randomized controlled trial of nephrostomy placement versus tubeless percutaneous nephrolitotomy. Urology 2008;180:612-4. http://dx.doi.org/10.1016/i. juro.2008.04.020

11. Beiko D, Lee L. Outpatient tubeless percutaneous nephrolithotomy: The initial case series. Can Urol Assoc J 2010;4:E86-90.

12. Shahrour W, Andonian S. Ambulatory percutaneous nephrolithotomy: Initial series. Urology 2010;76:128892. http://dx.doi.org/10.1016/i.urology.2010.08.001

13. Klinger, HC, Kramer, G, Lodde M, et al. Urolithiasis in allograft kidneys. Urology 2002;59:344-8. http:// dx.doi.org/10.1016/S0090-4295(01)01575-8

14. Stavodimos KG, Adamis $\mathrm{S}$, Tyritzis $\mathrm{S}$, et al. Renal transplant lithiasis: Analysis of our series and review of the literature. J Endouro 2012;26:38-44. http://dx.doi.org/10.1089/end.2011.0049

15. Wong KA, Olsburgh J. Management of stones in renal transplant. Curr Opin Uro 2013;13:175-9.

16. Oliveira $M$, Branco $F$, Martins $L$, et al. Percutaneous nephrolithotomy in renal transplants: A safe approach with a high stone-free rate. Int Urol Nephrol 2011;43:329-35.

17. de Cogain MR, Krambeck AE. Advances in tubeless percutaneous nephrolithotomy and patient selection: An update. Curr Urol Rep 2013;14:130-7. http://dx.doi.org/10.1007/s1 1934-013-0310-4

18. Kokorovic A, Wilson JW, Beiko, D. Outpatient bilateral supracostal tubeless percutaneous nephrolithotomy for staghorn calculi. Can Urol Assoc J 2014;8:e273-5. http://dx.doi.org/10.5489/cuaj.1691

19. Webb J, Soomro N, Jaques B, et al. The upside down transplant kidney. Clin Transplant 2003;17:484. http://dx.doi.org/10.1034/i.1399-0012.2003.00041.x

20. Simforoosh N1, Aminsharifi A, Tabibi A, et al. Right laparoscopic donor nephrectomy and the use of inverted kidney transplantation: An alternative technique. BJU Int 2007;100:1347-50. http://dx.doi. org/10.1111/i.1464-410X.2007.07134.xFigures

Correspondence: Dr. Darren Beiko, Associate Professor, Department of Urology, Queen's University, Kingston General Hospital, 76 Stuart St., Kingston, 0N K7L 2V7; beiko@queensu.co

This paper has been peer-reviewed. 